| Revista: Ciencia, Tecnología y Política | Año 1 Número 1 | www.revistas.unlp.edu.ar/CTyP |

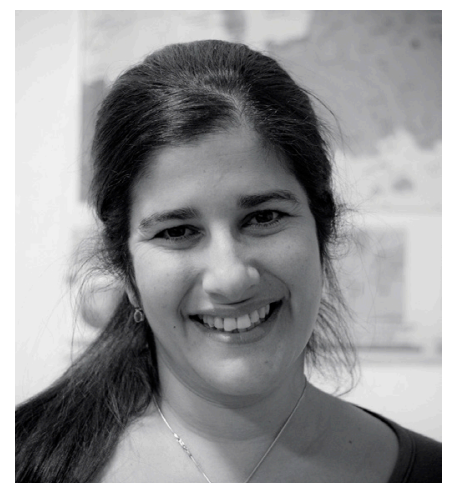

Tamara Perelmuter

Dra. en Ciencias Sociales.

Instituto de Estudios de

América Latina y el Caribe

(IEALC).

tamiperelmuter@gmail.com

\title{
Apropiación de semillas: soberanía alimentaria y tecnológica en riesgo
}

Resumen: Desde mediados del siglo veinte dos hechos impactaron decisivamente en la producción y comercialización de semillas: la aparición de las semillas híbridas, y la expansión de las biotecnologías aplicadas al agro, que condujo a un salto en la privatización del conocimiento. Las semillas adquirieron así un interés estratégico en el desarrollo de la agricultura global. En este trabajo se analizan estos procesos en Argentina y se discuten diversos dispositivos desarrollados en el país vinculados con esta temática. En particular la Ley de Semillas y los diversos intentos por modificarla; las disputas por el cobro de regalías y los contratos bilaterales entre Monsanto y productores. Se concluye, por un lado, que todo avance de la lógica de apropiación y eliminación de derechos de los agricultores a la resiembra pone en riesgo nuestra Soberanía Alimentaria. Por otro lado, se hace necesario un nuevo modelo agroalimentario basado en la agroecología, con eje en la producción de alimentos sanos y culturalmente apropiados, y en el cuidado de la biodiversidad y los recursos naturales.

Palabras clave: Semillas - Propiedad

Intelectual - Argentina - Soberanía alimentaria
Appropriation of seeds: food and technological sovereignty at risk

Abstract: Since the mid-twentieth century, two events had a decisive impact on the production and commercialization of seeds: the appearance of hybrid seeds, and the expansion of biotechnologies applied to agriculture, which led to a jump in the privatization of knowledge. The seeds thus acquired a strategic interest in the development of global agriculture. This paper analyzes these processes in Argentina and discusses various devices developed in the country related to this topic. In particular, the Law of Seeds and the various attempts to modify it; disputes over the collection of royalties and the bilateral contracts between Monsanto and the producers. It concludes, on the one hand, that any advance of the logic of appropriation and elimination of rights of the farmers to the reseeding puts in risk our Food Sovereignty. On the other hand, a new agrofood model based on agroecology is needed, with a focus on the production of healthy and culturally appropriate foods, and on the care of biodiversity and natural resources.

Keywords: Seeds - Intellectual Property Argentina - Food sovereignty 


\section{Introducción: Semillas en disputa}

Desde el nacimiento de la agricultura hasta hace no mucho tiempo, agricultores y agricultoras produjeron y reprodujeron sus propias semillas. El proceso de selección y mejora estuvo en sus manos, quienes recurrentemente guardaban e intercambiaban con otros productores distintas semillas para las siguientes estaciones.

A diferencia de otros productos, la semilla es un organismo vivo que puede reproducirse y es por esto que ha sido difícil transformarla en una mercancía. Sin embargo, el capital buscó siempre estrategias diversas para sortear las barreras derivadas del carácter natural de la agricultura (Bartra, 2008). A partir de mediados del siglo XX, acontecieron dos hitos en las transformaciones técnicas de las semillas que dieron pasos importantes en ese sentido: 1). Las aparición de las semillas híbridas (masificadas en el marco de la Revolución Verde') que rompieron la identidad semillas-grano y por lo tanto, significaron la separación del agricultor de su capacidad de replantar y el comienzo de la dependencia de las empresas que proveen los insumos; y 2). La expansión de las biotecnologías aplicadas al agro que dieron lugar a las semillas transgénicas, que condujo a grandes cambios en las estrategias de privatización del conocimiento; y en el uso y la reproducción de semillas habilitando nuevos mecanismos de acumulación de capital (López Monja, Poth y Perelmuter, 2008). Por lo tanto, las semillas se volvieron un punto de interés estratégico en el desarrollo de la agricultura global (Kloppenburg, 2005).

Las semillas son el primer eslabón de cualquier cadena agroalimentaria. De su posesión, producción y comercio, depende la soberanía alimentaria y el desarrollo agropecuario de un país. Quien controla las semillas, controla la cadena productiva y por lo tanto, la disponibilidad de alimentos. Actualmente el mercado de semillas comerciales es uno de los más concentrados y está controlado por un puñado de empresas transnacionales: si las megafusiones corporativas que actualmente se están negociando prosperan, solamente cuatro mega empresas monopolizarán más del $60 \%$ del mercado comercial de semillas a nivel mundial (ETC, 2018²).

Pero las semillas son también la base de la biodiversidad, y esta se ha convertido en una riqueza estratégica a explotar y controlar (Delgado Ramos, 2008). La preponderancia de la biotecnología y la posibilidad de manipular la información genética ha tornado al acervo genético de diversidad del planeta en uno de los

\footnotetext{
${ }^{1}$ La Revolución Verde fue la implementación de nuevas relaciones de producción agrarias expandidas desde mediados de los años cincuenta en América Latina como correlato de las formas de producción fordistas desarrolladas en las fábricas con la intención de lograr disminuir los costos de producción y maximizar las ganancias. Esta situación significó un cambio cualitativo y cuantitativo en el uso de insumos externos, donde al agro ingresaron nuevas tecnologías de mecanización, agroquímicos, semillas mejoradas y renovadas técnicas de irrigación conformando un paquete tecnológico. Partiendo de Estados Unidos y con el apoyo de la Fundación Ford y la Fundación Rockefeller, se crearon y financiaron en los países del Sur los Centros de Investigación Agrícola (IARC) que rápidamente se transformaron en actores desatacados de la política internacional de semillas.

${ }^{2}$ Las cuatro mega empresas son: 1. La resultante de la fusión entre Bayer y Monsanto; 2. Corteva Agriscience (una nueva empresa derivada, resultado de la fusión entre Dow y DuPont); 3. La empresa resultado de la unión entre Syngenta (con sede en suiza) y Chem China (compañía química china); y 4. La alemana BASF.
} 
| Revista: Ciencia, Tecnología y Política | Año 1 Número 1 | www.revistas.unlp.edu.ar/CTyP |

elementos más codiciados por los laboratorios científicos. Las "tecnologías de la vida", desarrolladas en los países del Norte, requieren del oro verde concentrado en los países del Sur (Heineke, 2002; Ceceña, 2001).

\section{Mecanismos jurídicos y cambios en las formas de apropiación}

En articulación con las transformaciones técnicas de las semillas, se produjeron mecanismos jurídicos que acompañaron los cambios en las formas de apropiación de las mismas: leyes de semillas, que exigen el obligatorio registro y certificación; contratos que realizan las empresas de manera asimétrica con los productores; y sobre todo, legislaciones de propiedad intelectual.

Hay dos formas de reconocer la propiedad intelectual aplicada a semillas. Por un lado, los derechos de obtentor (DOV que son otorgados a quién desarrolla alguna "mejora" a una semilla (puede ser mediante transgénesis, hibridación o mejoramiento tradicional), para explotarla en exclusividad, pero no alcanza al producto obtenido. Por otro lado, las patentes de invención, que son derechos exclusivos otorgados por el Estado a una invención, es decir, a un producto o procedimiento que aporta una nueva manera de hacer algo. En el caso específico de las semillas, la protección involucra al producto y las sucesivas generaciones del vegetal. Los DOV son válidos para todo tipo de semillas, a diferencia de las patentes, que son sólo para las semillas transgénicas en tanto solo se protege la modificación genética ${ }^{3}$.

Hasta los años sesenta, los materiales vegetales utilizados para el mejoramiento genético eran de libre acceso. Este principio comenzó a resquebrajarse cuando la regulación en torno a la protección de DOV a nivel internacional se institucionalizó en 1961 con el nacimiento de la Unión para la Protección de Variedades Vegetales (UPOV) ${ }^{4}$.

La versión 78 de UPOV contempla implícitamente el derecho de los agricultores. Significa que éstos, a excepción de su venta comercial, conservan el derecho a producir libremente sus semillas pudiendo utilizar el producto de la cosecha que hayan obtenido por el cultivo en su propia finca. Es lo que se conoce como el uso propio de las semillas.

Hasta los años ochenta las patentes sobre organismos vivos no estaban permitidas. Sin embargo, el fallo Diamond-Chakrabarty de la Corte Suprema de Estados Unidos, que admitió una patente sobre una bacteria modificada capaz de separar los componentes de petróleo crudo, constituyó una bisagra al delimitar lo que es patentable y lo que no ${ }^{5}$. Se abrió así un nuevo e inmenso campo para la propiedad intelectual, descono-

\footnotetext{
${ }^{3}$ Originalmente, las diferencias entre éstas eran marcadas. Pero la importante ofensiva de los últimos años por profundizar los derechos de propiedad intelectual en el ámbito de la biodiversidad está llevando a una inclusión, en el derecho de obtentor, de elementos propios de las patentes.

${ }^{4}$ La Unión Internacional para la Protección de las Obtenciones Vegetales (UPOV) es una organización intergubernamental con sede en Ginebra (Suiza). Fue creada por el Convenio Internacional para la Protección de las Obtenciones Vegetales. El Convenio fue adoptado en París en 1961, y fue revisado en 1972, 1978 y 1991.

${ }^{5}$ La decisión radicó en considerar a la bacteria en cuestión como una manufactura ya que su existencia se debía a una manipulación genética, en decir, a una invención del hombre.
} 
cido anteriormente: la propiedad intelectual sobre formas de vida (Bartra, 2008).

A partir de los años noventa, empresas transnacionales semilleras y biotecnológicas comenzaron a presionar para lograr una armonización internacional de la legislación de propiedad intelectual. En ese sentido, UPOV se reformuló en 1991 recortando las excepciones del acta de 1978, que otorgaba algunos derechos a los nuevos fitomejoradores y a los agricultores.

Asimismo, las transformaciones más profundas en relación a la propiedad intelectual comenzaron a realizarse a través de la Organización Mundial del Comercio (OMC) y uno de los principales acuerdos introducidos en 1995 fue sobre los Aspectos de los Derechos de Propiedad Intelectual que afectan al Comercio (ADPIC). En relación con las patentes, el acuerdo representa una clara profundización en los intentos de apropiación de conocimiento ampliando el alcance de lo que se considera patentable.

\section{Dispositivos de apropiación de semillas en Argentina}

En Argentina el debate sobre la forma en que diversos sectores se apropian de las semillas es central. Se trata de un país pionero en América Latina en la protección de semillas mediante propiedad intelectual. Asimismo, adoptó tempranamente las semillas transgénicas (1996) generando importantes transformaciones del modelo agroalimentario (Teubal, 2006) y de manera paralela las leyes que regulan la propiedad intelectual en semillas, fueron reformadas para la misma época. Y, finalmente, desde 2003 existen intentos por modificar nuevamente la Ley de Semillas, con la intención de brindarle mayores certidumbres económicas a las empresas, recortando derechos de los productores.

Las disputas en torno a la apropiación de las semillas son múltiples y se dan a partir de una serie de dispositivos que se multiplicaron y complejizaron en los últimos años: 1) la Ley de Semillas y los diversos intentos por modificarla; 2) las disputas por el cobro de las regalías de la soja RR; 3) los contratos bilaterales firmados por Monsanto y los productores (Perelmuter, 2017).

\section{La Ley de Semillas y el debate por el uso propio}

La Ley de Semillas vigente en nuestro país data del año 1973 y reúne dos elementos: legisla sobre todo lo referido a la producción, certificación y comercialización de semillas (no sólo las transgénicas) y establece la regulación de una de las formas de propiedad intelectual sobre variedades vegetales: los Derechos de Obtentor (DOV).

En su artículo 27, reconoce que no lesiona ese derecho quien reserva y siembra semilla para uso propio, es decir, en su propia explotación. Por lo tanto las semillas de uso propio son consideradas legales. Son aquellas que fueron adquiridas directamente de las empresas, certificadas por el Estado y que los productores utilizan para sí mismos. Esto aparece la mayoría de las veces en los discursos de las empresas y del Estado confundido con la denominada bolsa blanca, es decir, con las semillas ilegales: aquellas que son comercializadas por fuera de los círculos considerados legales en tanto carecen de rótulos que ga- 
rantizan su origen, calidad y variedad.

Lo que no existen son datos certeros acerca de qué porcentaje de semillas corresponde a cada una de estas modalidades ${ }^{6}$. Pero desde un tiempo a esta parte, las empresas del sector vienen "acusando" con gran ahínco al uso propio de ser el responsable de la bolsa blanca (Perelmuter, 2017). Las empresas dedicadas a la investigación y desarrollo de organismos genéticamente modificados con fines agrícolas aducen que el problema es el mercado ilegal, que no permite realizar una captura de valor por el germoplasma y los eventos transgénicos (Vilella et al, 2010). Y por lo tanto, vienen presionando para modificar la Ley de Semillas.

A partir de 2012 esta discusión tomó un impulso importante y se abrió una "mesa de negociaciones" en el marco de la CONASE (Comisión Nacional de Semillas), de la que participaron miembros de organismos públicos ${ }^{7}$, del sector privado ${ }^{8}$ y de las entidades de productores agrarios ${ }^{9}$. Ni las organizaciones campesinas e indígenas; ni aquellas relacionadas con la denominada agricultura familiar; ni las universidades nacionales y los organismos públicos de investigación como el CONICET, fueron consultados ni incorporados formalmente al debate. La Federación Agraria Argentina (FAA) formuló su rechazo y se retiró de la mesa de negociaciones. Ante la falta de acuerdos, ninguno de los anteproyectos en discusión salió de la órbita del Ministerio de Agricultura.

Sin hacerlo explícito, las versiones en cuestión tomaban algunos elementos de UPOV 91: se buscaba restringir el uso propio, al tiempo que incrementar sanciones, otorgando a las empresas el poder de policía para controlar y fiscalizar los campos en el caso de que se presuma que la ley no se cumple. Esto generó el rechazo por parte de organizaciones sociales, políticas (incluso algunas que eran afines al gobierno), campesinas, indígenas y de la agricultura familiar.

A fines de 2016 el gobierno de Cambiemos presentó su propuesta, que fue negociada en secreto. Al igual que el resto de los anteproyectos, acotaba la figura del uso propio ${ }^{10}$. Asimismo, algunos sectores de la oposición política también presentaron proyectos. Pero la gran novedad fue la presentación de pro-

\footnotetext{
${ }^{6}$ Para ARPOV (Asociación Argentina de Protección de las Obtenciones Vegetales), sólo el 15\% de las hectáreas dedicadas al cultivo de soja han sido sembradas con semillas certificadas. Sin embargo, este dato involucra tanto semillas que corresponden a uso propio, como a semillas que no.

${ }^{7}$ Participaron el INTA (Instituto Nacional de Tecnología Agropecuaria), el INASE (Instituto Nacional de Semillas) y el Ministerio de Agricultura, Ganadería y Pesca.

${ }^{8}$ Participaron ASA (Asociación de Semilleros Argentinos); CASEM (Cámara Argentina de Semilleros Multiplicadores); AACREA (Asociación Argentina de Consorcios Regionales de Experimentación Agrícola) y AAPRESID (Asociación de Productores de Siembra Directa).

${ }^{9}$ Las entidades en cuestión son FAA (Federación Agraria Argentina), SRA (Sociedad Rural Argentina), CONINAGRO (Confederación Intercooperativa Agropecuaria) y CRA (Confederaciones Rurales Argentinas).

${ }^{10}$ El proyecto explicitaba que, tras la compra de la semilla, el productor deberá pagar un derecho a las empresas por las siguientes tres campañas si siembra por la misma superficie comprada. Al cuarto ciclo no debía pagar más, salvo que hiciere una superficie mayor, con lo cual debería abonar la diferencia. Además, contemplaba como agricultores exceptuados a los productores de agricultura familiar, pueblos originarios y quienes tengan una facturación anual menor a 1,8 millones de pesos (tres veces la categoría más alta del monotributo). No explicitaba cómo se determinará quiénes se encuentran dentro de cada categoría.
} 
puestas por parte de una entidad de productores (Federación Agraria Argentina) y una cámara empresarial (Asociación de Semilleros Argentinos). Este último anteproyecto avanzaba mucho más en el recorte del uso propio que el proyecto del oficialismo al no plantear siquiera excepciones. Si bien hubo algunas reuniones de la comisión de agricultura para la discusión del tema, no hubo acuerdos y por lo tanto, los proyectos perdieron estado parlamentario y sigue sin resolverse la modificación de la Ley de Semillas.

\section{Las disputas por el cobro de regalías}

En 1996 la Secretaría de Agricultura, Ganadería, Pesca y Alimentos (SAGPyA) le otorgó la licencia a Monsanto para comercializar la soja RR (Roundup Ready) junto al glifosato, herbicida al cual el cultivo es resistente. Se trató de la incorporación de insumos relativamente baratos (semillas y herbicidas), porque no incluía pago alguno en concepto de regalías por el uso del gen RR ya que Monsanto en Argentina no patentó la semilla en cuestión. La Soja RR fue difundida en este país por empresas con gran arraigo local, como Nidera (Pellegrini, 2011). Su difusión se dio de manera vertiginosa con una ventaja importante para Monsanto ya que esta empresa vendía también el herbicida (glifosato), al que la planta de soja se hace resistente, beneficiándose con las ventas de crecientes volúmenes del herbicida. En el año 2000 la patente sobre el agroquímico se venció y el mercado comenzó a inundarse de ese producto que venía de China, a mitad de precio. En 2002 Monsanto comenzó una campaña legal para acusar a las importaciones chinas de hacer dumping ${ }^{11}$ pero el gobierno argentino rechazó estos reclamos permitiendo que el glifosato chino siga en el mercado local (Arza, 2014).

El accionar de Monsanto se volvió más agresivo comenzando a ejercer intimidaciones a los productores por el supuesto uso ilegal de las semillas, amenazando con salirse del mercado argentino y cobrando regalías en los puertos de destino de exportación de la soja de aquellos países donde sí tienen la patente (Teubal 2006; Correa 2004). El Estado argentino fue a juicio internacional con la empresa ${ }^{12}$. En 2010 la Suprema Corte de Justicia de la Unión Europea dictaminó a favor de la Argentina ${ }^{13}$.

Contemporáneamente a los reclamos de Monsanto por la patente del gen de la soja RR, el intento por cobrar regalías se hizo por otros medios. Por un lado, desde 2003 la Asociación Argentina de Protección de las Obtenciones Vegetales (ARPOV) intenta legalizar el cobro permanente por el uso de las semillas mediante una modalidad de comercialización denominada regalía extendida. Se busca que la regalía propia del licenciamiento para la producción y comercialización de semillas, se extienda también a las sucesivas siembras que el agricultor realice con semillas de su propia cosecha. El productor agrícola es

\footnotetext{
${ }^{11}$ Nos referimos a la práctica comercial que consiste en vender un producto por debajo de su precio normal, o incluso por debajo de su coste de producción, con el fin inmediato de ir eliminando las empresas competidoras y apoderarse finalmente del mercado.

12 La posición del gobierno argentino se centró en calificar de extorsiva la conducta de Monsanto, argumentando que las demandas a los importadores, aun tratándose de un conflicto entre privados, tenía el fin de provocar una traba injustificada al comercio legítimo de harina de soja argentina.

${ }^{13}$ El fallo sostenía que la compañía "no puede prohibir" la comercialización en Europa de la harina de soja argentina que contiene, en estado residual, una secuencia de ADN patentada por la empresa estadounidense en algunos países de Europa pero no en Argentina.
} 
obligado a pagar por el uso del material derivado del originariamente adquirido, en la medida en que lo vuelva a sembrar en su explotación. Se altera así el régimen de la excepción del agricultor que permite el uso propio en forma gratuita.

El sistema generó grandes controversias, entre otras cosas, debido a que se trata de contratos de índole privado. Incluyen una cláusula que autoriza a ARPOV a enviar inspectores para verificar la ausencia de la reproducción ilegal, el uso y la comercialización de semillas en campos y lugares de acopio. Para las organizaciones de productores, el derecho a guardar semillas (y la ley de semillas en su totalidad) es de orden público y, por tanto, no pueden ser objeto de renuncia por un productor individual rural en un contrato privado (Filomeno, 2012).

Por otro lado, en 2004 la Secretaría de Agricultura, Ganadería, Pesca y Alimentos (SAGPyA) presentó una propuesta de elaboración de una regalía global o Fondo Fiduciario de Compensación Tecnológica e Incentivo a la Producción de Semillas conformada por una tasa a la venta de cosecha destinada a compensar a los obtentores. Se proyectaba que dicho Fondo actuara en el ámbito del INASE y fuera administrado por una Comisión integrada por representantes de los obtentores, los usuarios y del organismo de la SAGPYA. Debido al rechazo que tuvo por parte de la mayoría de los actores vinculados al mercado de las semillas, la propuesta de regalías globales no fue implementada.

\section{Contratos entre Monsanto y productores de soja.}

En 2012 la multinacional implementó contratos bilaterales con los productores luego de lanzar comercialmente su "gran novedad": la soja transgénica "Intacta RR2 Pro", resistente a herbicidas y tolerante a insectos. Se trata de un sistema de Licencia de Uso para su nueva soja, que no es otra cosa que un contrato de regalía extendida, mediante el cual se impone a quien quiera usar la soja, la firma de un contrato con vigencia hasta 2028, por el cual el productor asume el compromiso de pagar una contraprestación por el uso de la tecnología y realizar el "uso correcto de la tecnología" cada vez que vuelva a sembrar la soja Intacta. Además, establece la obligación de comprar las semillas a Nidera, Don Mario y ACA (Asociación de Cooperativas Argentinas), dispone quién va ser el 'acopiador' de la producción y quién el exportador, controlando de esta manera la totalidad de la cadena. Los contratos marcan también que se retendrá la cosecha hasta tanto no se haya pagado efectivamente la regalía extendida a las semilleras. Tienen además cláusulas penales para el caso de incumplimientos por parte del productor.

Sin embargo, la soja Intacta no dio los frutos esperados, y los productores no firmaron masivamente este contrato. En ese sentido, para los años 2013 y 2014 la siembra de la soja Intacta se multiplicó a partir de la comercialización del grano cosechado en la anterior cosecha, vendido ilegalmente como semilla. Ante este panorama, Monsanto intentó cobrar las regalías realizando controles en los silos de los puertos del litoral argentino, donde el grano es acopiado para su exportación desatándose así un conflicto ante la negativa de varios productores a aceptar este control.

El gobierno de Cambiemos ganó las elecciones con el apoyo más o menos explícito de sectores de 
productores, incluyendo a las organizaciones que componían la Mesa de Enlace ${ }^{14}$. Por lo tanto, mediar y resolver este conflicto parece ser una prioridad importante. En ese sentido, a mediados de 2016 estableció mediante la resolución 107/06 el sistema BolsaTech, patrocinado por la Bolsa de Cereales de Buenos Aires y que consiste en establecer la "trazabilidad" de la información que se utiliza para los controles ${ }^{15}$. De esta manera, el Estado se hace cargo de controlar el origen de las semillas, en defensa de los intereses de los Ilamados "obtentores". La norma estuvo pensada sólo para la campaña 2016/17, ya que el Gobierno confiaba en que habría una nueva ley de semillas para la campaña siguiente. Pero como esto no ocurrió, el sistema se extendió a la campaña 2017/18.

\section{Algunas reflexiones finales}

Con más de la mitad de su tierra cultivable sembrada con semillas transgénicas, Argentina resulta un lugar estratégico para analizar los conflictos en torno a la apropiación de las semillas. Se trata de un debate que va mucho más allá de una discusión legal o una disyuntiva técnico productiva. En efecto, tiene que ver con discutir el modelo agrario y, por lo tanto, el proyecto de país.

Los derechos para cultivar, guardar, reproducir y usar semillas son un campo de batalla clave para determinar quién controla la alimentación y la agricultura. Las semillas son el primer eslabón de la cadena alimentaria y, por lo tanto, todo lo que pase con ellas repercute directamente sobre los alimentos que consumimos, sobre sus precios y su calidad, pero también sobre la soberanía de esos alimentos, y sobre quién decide qué se produce y qué se consume en el país.

Asimismo, en concordancia con Correa (2013), entendemos que no hay demostración fehaciente ni garantía de que el desarrollo y la innovación tecnológica dependan de los retornos económicos por parte de las empresas. La mayor parte de las experiencias de mejoramiento es realizada in situ por los agricultores, y por la producción pública de conocimiento en las Universidades e instituciones técnico-científicas estatales como CONICET, INTA e INTI. Por lo tanto, la única vía real de independencia en materia de semillas es el fortalecimiento de la investigación pública. Pero entendiendo que esto también es un campo de disputa. Lo que debemos propugnar es por una investigación pública que se enfoque en la aplicación de medidas de resguardo y fomento de los agricultores que realizan día a día el mejoramiento de nuestras variedades.

\footnotetext{
${ }^{14}$ La Mesa de Enlace estuvo compuesta por la Sociedad Rural Argentina (SRA), Confederaciones Rurales Argentinas (CRA) y Confederación Intercooperativa Agropecuaria (CONINAGRO) y la Federación Agraria Argentina (FAA). Surgió en 2008 en el contexto del denominado Conflicto del Campo, que se estructuró en torno a la Resolución n 125/2008 durante presidencia de Cristina Fernández de Kirchner, que establecía un sistema móvil para las retenciones impositivas a la soja, el trigo y el maíz. 15 "Para la cosecha de soja Campaña 2015/16, le serán extraídas al productor o remitente muestras de grano en el primer punto de entrega las cuales podrán ser requeridas por el Instituto Nacional de Semillas, organismo descentralizado en la órbita del Ministerio de Agroindustria, para la verificación del cumplimiento de la Ley de Semillas y Creaciones Fitogenéticas N²0.247 (ley de semillas)", dice el primer artículo de la resolución 207.
} 
| Revista: Ciencia, Tecnología y Política | Año 1 Número 1 | www.revistas.un|p.edu.ar/CTyP |

Todo avance de la lógica de apropiación y eliminación de los derechos de los agricultores a la resiembra de su cosecha, aún con excepciones de los pequeños y medianos productores, es un retroceso en derechos adquiridos y pone en riesgo la base fundamental de nuestra Soberanía Alimentaria. Por lo tanto, sería urgente y necesario avanzar en políticas de transición hacia otro modelo agroalimentario basado por un lado en la agroecología, que ponga el eje en la producción de alimentos sanos y culturalmente apropiados. Por otro lado en en el cuidado de la biodiversidad y el resto de los recursos naturales, que son, antes que nada, bienes comunes de toda la humanidad

\section{Bibliografía}

Bartra, A. (2008). El hombre de hierro. Los límites sociales y naturales del capital. México DF: Editorial Itaca.

Ceceña A.E. (2001). La territorialidad de la dominación: Estados Unidos y América Latina. Revista Chiapas, № 12, México,

Correa C. (2004). Monsanto vs. Argentina. Le Monde Diplomatique, Edición Cono Sur, №82.

Correa C. (2013). Texto publicado en ENCUENTRO LEY DE SEMILLAS EN LA BIBLIOTECA NACIONAL, Qué opina cada sector. Buenos Aires: Toctumi Ediciones.

Delgado Ramos, G. C. (2008). El carácter geoeconómico y geopolítico de la biodiversidad: el caso de América Latina. En Gestión ambiental y conflicto social en América Latina. Buenos Aires: CLACSO.

ETC (2018). Bayer-Monsanto y la mega fusión de la industria de semillas y pesticidas. Recuperado de http://www.iade.org.ar/noticias/bayer-monsanto-y-la-mega-fusion-de-la-industria-de-semillas-y-pesticidas.(18/06/18)

Heineke, C. (2001). La fiebre del Oro Verde en Heineke, Corinna. La vida en venta: Transgénicos, patentes y diversidad biológica. México: Fundación Heinrich Böll.

Kloppenburg, J. (2005). First the seed: the political economy of plant biotechnology. 2. ${ }^{a}$ ed. Madison: University of Wisconsin Press.

López Monja C., Poth C. y Perelmuter T. (2010). El avance de la soja transgénica, ¿progreso científico o mercantilización de la vida? Un análisis crítico a la biotecnología agraria en Argentina. Buenos Aires: Ediciones Centro Cultural de la Cooperación.

Pellegrini, P. (2011). Agricultura transgénica: modos de producción y uso del conocimiento científico. Ciencia, Estado e industria en los cultivos transgénicos en Argentina, Tesis de Doctorado, FLACSO- Universite Sorbonne- Paris IV.

Perelmuter T. (2017). El rol de la propiedad intelectual en los actuales procesos de cercamientos. El caso de las semillas en la Argentina (1973 - 2015). Tesis para optar por el título de Doctora en Ciencias Sociales Facultad de Ciencias Sociales, UBA.

Teubal M. (2006). Expansión del modelo sojero en la Argentina. De la producción de alimentos a los commodities. Revista Realidad Económica Nª 220. Buenos Aires: IADE.

Vilella, F., Senesi, S. I., Dulce, E. G., Pérez San Martín, R., Daziano, M. F. (2010), El sistema de agronegocios de la soja en la Argentina: su cadena y prospectiva al 2020. Buenos Aires: Ed. Horizonte. 